\title{
Unified Power Flow Controller: Modeling And Dynamic Characteristic
}

\author{
Ho Dac Loc \\ Hochiminh City University of Technology (HUTECH), Hochiminh City
}

\begin{abstract}
Unified power flow controller (UPFC) consists two converters. There are three purposes of this paper, firstly to illustrate the UPFC device based VSC designs, then to describe a decoupling method the UPFC's controller into two separate control systems of the shunt and the series converters respectively in realizing an appropriate co-ordination between them. Finally, using the Matlab tool to build a discrete simulator for the UPFC with 12 pulse converters. The simulation results show that the developed UPFC model is reflected the static and dynamic characteristics of the UPFC. The harmonics of the output of the model are analyzed. Using the simple power system with UPFC as an example, the dynamics characteristics are studied. The fault status of the system with UPFC is analyzed too.
\end{abstract}

Keyword list: - Times Roman, image area, acronyms, references

\section{INTRODUCTION}

The developing interest in tools for power flow control in a power system has increased significantly during the last 10 years. Demand for research in this field is motivated by rapid transformations in both technology and organization of the power system industry [1]. The deregulation and competitive environment in the contemporary power networks will imply a new scenario in terms of load and power flows condition and so causing problems of line transmission capacity. For this reason, Flexible AC Transmission System (FACTS) controllers has rapidly developed to meet the need for increasing transmission capacity and controlling power flows through predefined transmission corridors. Especially, the improvements in the field of power electronics have had a major impact on the development of this technology. The devices of new FACTS generation are based on the use of high power electronic components such as GTO (Gate Turn-Off Thyristor) and IGBT (Insulated Gate Bipolar Transistor) which makes them respond quickly to the control requirements. It is called by the FACTS technologies based on Voltage Sourced Converter (VSC) designs. The wider application of FATCS leads to numerous benefits for electrical transmission system infrastructure, including increased capacity at minimum cost; enhanced reliability through proven performance; higher levels of security by means of sophisticated control \& protection; and improved system controllability with state-of-the-art technology concepts. Thereby, these FACTS devices are able to act almost instantaneously to changes in power system [2]. The most powerful in family of FACTS devices is the Unified Power Flow Controller (UPFC), because it can control simultaneously all three parameters of transmission power line (line impedance, voltage and phase angle). In practice, the UPFC device consists of two Voltage Source Converters (VSC) connected respectively in shunt and in series with the transmission line, and connected to each other by a common DC link including a storage capacitor. The shunt converter is used for voltage regulation at the point of connection injecting an opportune reactive power flow into the line and to balance the real power flow exchanged between the series converter and the transmission line. The series converter can be used to control the real and reactive line power flow inserting an opportune voltage with controllable magnitude and phase in series with the transmission line. Thereby, the UPFC can perform functions of reactive shunt compensation, active and reactive series compensation and phase shifting [3]. There are many different UPFC models have been investigated by several authors [4-6]. The three main purposes of the paper are firstly to illustrate the UPFC configuration based on VSC's, and then describe a decoupling method the UPFC's controller into two separate control systems of the shunt and the series converters respectively in realizing an appropriate co-ordination between them, and finally to simulate a new discrete UPFC model based on 12-pulse VSC using Matlab Power Block/Simulink as simulation program. Besides, PWM method is applied to decrease total of voltage harmonics in simulation output of converters.

\section{THE UPFC CONFIGURATION- BASED VOLTAGE SOURCE CONVERTER}

\section{VSC design concept}

The single-line diagram of the UPFC is a combination of two VSC configurations shown in Figures 1. As shown in Figures 1, VSC designs are composed of two basic configurations:

A) Shunt Connected VSC System, and 
B) Series Connected VSC System

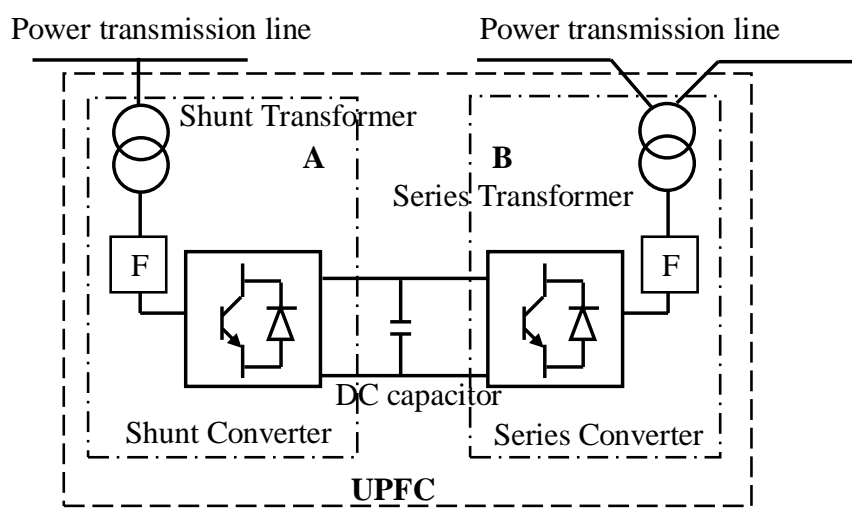

Figure 1 - the UPFC configuration.

A basic schematic diagram of the VSC design is illustrated in Figure 2. As a typical configuration, the VSC is a six-pulse converter consisting of six power semiconductor switching devices (GTO, GCT, IGBT, etc) with anti-parallel connected diode together with heat sinks and auxiliary equipment for gating, monitoring and grading. In a high power converter, a number of semiconductor devices may be connected in series or in parallel. Some advanced configurations, for example connecting cascade of two six-pulse converters to twelvepulse converter, have developed to reduce total of voltage harmonics of converter outputs in Fig. 3.

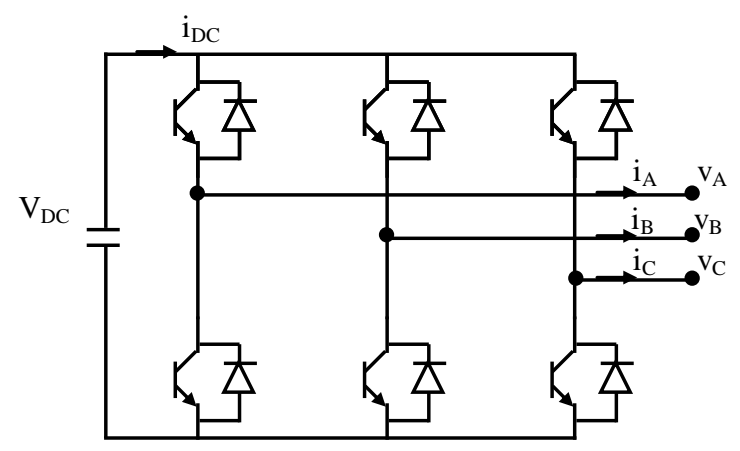

Figure 2 - Basic VSC Schematic Diagram

From a point of D.C. voltage source, provided by a charged capacitor $\mathrm{C}_{\mathrm{S}}$, the converter produces a set of controllable three-phase output voltages at the fundamental harmonic frequency of the A.C. system voltage. The output voltage waveform may be a square waveform (Figure 4.a) or a pulse width modulated (PWM) waveform (Figure 4.b), depending on circuit topology and pulse modulation method.

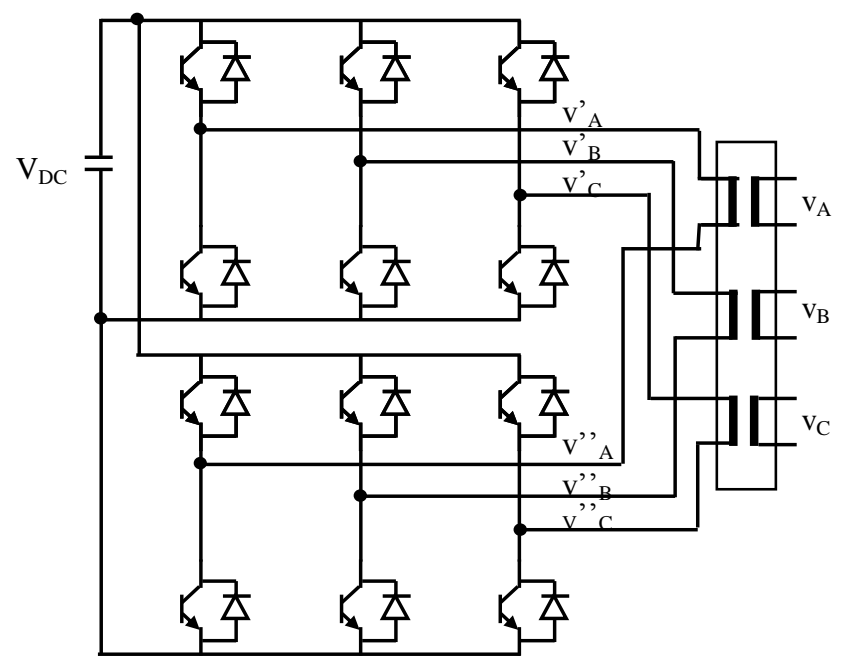

Figure 3 - 12 Pulse-VSC Schematic Diagram 
In order to eliminate harmonic content from the output voltage, various techniques can be adopted. A multiple-pulse arrangement by combining the output of cascade or parallel VSCs can be adopted as a solution using a multi-winding transformer or inter-phase transformer magnetic. The pulse width modulation (PWM) technique can be implemented to control harmonic content from the output voltage too. Moreover, harmonic filters can be also adopted in combination with the above techniques. In this paper PWM control is utilized, allowing for simplified two winding interconnecting transformer designs.

\section{(a)}

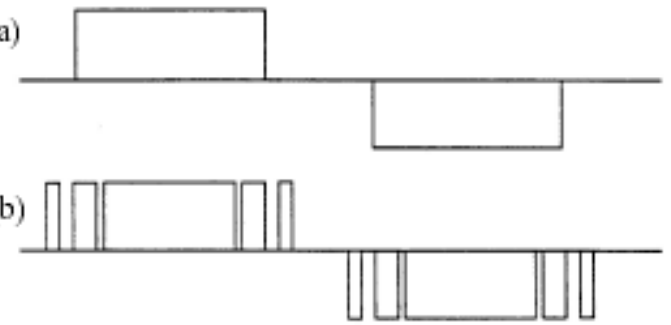

Figure 4 - VSC Output Voltage Waveforms

In the configuration of UPFC, there are two independent VSCs interconnected via coupling capacitor as Shunt converter and Series converter.

Shunt Connected VSC - the VSC is connected to the power system via a shunt connected transformer. By varying the amplitude and the phase of the output voltages produced, the active power and the reactive power exchange between the converter and the A.C. system can be controlled in a manner similar to that of a rotating synchronous machine. If the amplitude of the output voltage is increased above that of the AC system voltage, the VSC generates reactive power to the power system. If the amplitude of the output voltage is decreased below that of the AC system voltage, the VSC absorbs reactive power from the power system.

Series Connected VSC - the VSC is connected to the power system in series via a series connected transformer. By varying the amplitude and the phase of the output voltages produced, the magnitude and the angle of the injected voltage can be controlled. The VSC output voltage injected in series with the line acts as an AC voltage source. The current flowing through the VSC corresponds to the line current. The VA rating of the VSC is determined by the product of the maximum injected voltage and the maximum line current.

\section{Instantaneous power flow delivered by a VSC into a power system}

A converter connected to a power system, which is able of power exchange between the power system and the DC storage capacitor, can be represented by a three symmetrical sinusoidal voltage sources. A symmetrical three-phase system can be transformed into a synchronously-rotating orthogonal system. A new coordinate system, having the axes rotating at the synchronous angular speed of the fundamental network voltage $\square$, is defined on the basis of the dq transformation. In the Fig. 2 the VSC is supplied by a voltage system vector $\mathrm{V}_{\mathrm{S}}=\left(\mathrm{V}_{\mathrm{SA}}, \mathrm{V}_{\mathrm{SB}}, \mathrm{V}_{\mathrm{SC}}\right)$, with $\mathrm{R}$ and $\mathrm{L}$ are respectively the transformer equivalent resistances and inductances. The $\mathrm{d}-\mathrm{q}$ transformation of the supply voltage system $\mathrm{V}_{\mathrm{S}}$ is made using the following equations:

$$
\left[\begin{array}{c}
\mathrm{V}_{\mathrm{SD}} \\
\mathrm{V}_{\mathrm{SQ}}
\end{array}\right]=\left[\begin{array}{ccc}
1 & -\frac{1}{2} & -\frac{1}{2} \\
0 & \frac{\sqrt{3}}{2} & -\frac{\sqrt{3}}{2}
\end{array}\right]\left[\begin{array}{c}
\mathrm{V}_{\mathrm{SA}} \\
\mathrm{V}_{\mathrm{SB}} \\
\mathrm{V}_{\mathrm{SC}}
\end{array}\right]
$$

where :

$$
\begin{aligned}
& \omega=\frac{\mathrm{d} \theta}{\mathrm{dt}} ; \\
& \theta=\operatorname{arctg}\left(\frac{\mathrm{V}_{\mathrm{SQ}}}{\mathrm{V}_{\mathrm{SD}}}\right)
\end{aligned}
$$

On the basis of this $\mathrm{d}-\mathrm{q}$ transformation, the instantaneous active and reactive power flowing into the power system delivered by the VSC [6], neglecting transformer losses and balanced condition; and choose $\mathrm{V}_{\mathrm{SD}}$ $=\square \mathrm{V}_{\mathrm{SA}} \square, \mathrm{V}_{\mathrm{SQ}}=0$ are : 
$\mathrm{P}(\mathrm{t})=\frac{3}{2} \mathrm{~V}_{\mathrm{SD}} \mathrm{xI} \mathrm{I}_{\mathrm{SD}}$

$\mathrm{Q}(\mathrm{t})=\frac{3}{2} \mathrm{~V}_{\mathrm{SD}} \mathrm{xI} \mathrm{I}_{\mathrm{SQ}}$

where $\mathrm{V}_{\mathrm{SD}}, \mathrm{V}_{\mathrm{SQ}}, \mathrm{I}_{\mathrm{SD}}, \mathrm{I}_{\mathrm{SQ}}$ are vectors of d-q transition voltage and current respectively.

\section{DECOUPLING METHOD OF UPFC MODEL}

\section{Series and Shunt converter control systems}

In the UPFC configuration two converters can work independently of each other by separating the DC side. In general operating mode of UPFC is possible as follow:

a The series converter is operating in Automatic Power Flow Control mode: the reference inputs are value of $\mathrm{P}$ and $\mathrm{Q}$ to maintain on the transmission line despite system changes; and

a the shunt converter operating in Automatic Voltage Control mode : the goal is to maintain the transmission voltage line as a reference value.

In this paper it has been chosen a UPFC model in terms of two ideal controllable voltage sources, connected respectively in series and in shunt to the transmission line as in Fig. 1, to represent respectively the series and the shunt inverters. So, the two UPFC control systems must be developed in such a way to evaluate the amplitude and the phase angle of these two voltage sources on the basis of operating functions required UPFC. On the basis of (2) the instantaneous power flow at the receiving end, assuming $\mathrm{V}_{\mathrm{rD}}$ equal to the receiving end voltage amplitude $\mathrm{V}_{\mathrm{r}}$ and $\mathrm{V}_{\mathrm{Rq}}=0$ results:

$$
\begin{aligned}
& \mathrm{p}_{\mathrm{r}}(\mathrm{t})=\frac{3}{2} \mathrm{v}_{\mathrm{rD}} \mathrm{xi} \mathrm{i}_{\mathrm{rD}} \\
& \mathrm{q}_{\mathrm{r}}(\mathrm{t})=\frac{3}{2} \mathrm{v}_{\mathrm{rD}} \mathrm{xi} \mathrm{i}_{\mathrm{rQ}}
\end{aligned}
$$

where $i_{r D}$ and $i_{r Q}$ are the $d-q$ component values of line current. Thereby, the reference parameters of controller is possibly calculated as follows :

$$
\begin{aligned}
& \mathrm{i}_{\mathrm{rD}}^{*}(\mathrm{t})=\frac{2}{3} \frac{\mathrm{p}_{\mathrm{r}}^{*}}{\mathrm{v}_{\mathrm{rD}}} \\
& \mathrm{i}_{\mathrm{rQ}}^{*}(\mathrm{t})=\frac{2}{3} \frac{\mathrm{q}_{\mathrm{r}}^{*}}{\mathrm{v}_{\mathrm{rD}}}
\end{aligned}
$$

with $\mathrm{p}_{\mathrm{r}}^{*}$, and $\mathrm{q}_{\mathrm{r}}{ }_{\mathrm{r}}$ are the instantaneous active and reactive power flow required the receiving end.

At the same way, the instantaneous active and reactive power flows provided by the shunt inverter are:

$$
\begin{aligned}
& \mathrm{p}_{\mathrm{Sh}}(\mathrm{t})=\frac{3}{2} \mathrm{v}_{\mathrm{ID}} \mathrm{xi}_{\mathrm{Sh}, \mathrm{D}} \\
& \mathrm{q}_{\mathrm{Sh}}(\mathrm{t})=\frac{3}{2} \mathrm{v}_{\mathrm{ID}} \mathrm{xi}_{\mathrm{Sh}, \mathrm{Q}}
\end{aligned}
$$

also assuming $V_{I D}$ equal to the sending end voltage amplitude $V_{1}$ and $V_{1 Q}=0$, with $i_{S h, D}$ and $i_{S h, Q}$ are the $d-q$ current components injected by shunt inverter into the transmission line. So, the reference values of these two current components are evaluated as follows:

$$
\begin{aligned}
& \mathrm{i}_{\mathrm{Sh}, \mathrm{D}}^{*}(\mathrm{t})=\frac{2}{3} \frac{\mathrm{p}_{\mathrm{Sh}}^{*}}{\mathrm{v}_{\mathrm{ID}}} \\
& \mathrm{i}_{\mathrm{Sh}, \mathrm{Q}}^{*}(\mathrm{t})=\frac{2}{3} \frac{\mathrm{q}_{\mathrm{Sh}}^{*}}{\mathrm{v}_{\mathrm{ID}}}
\end{aligned}
$$

where $\mathrm{p}_{\mathrm{Sh}}^{*}, \mathrm{q}_{\mathrm{Sh}}^{*}$ are the instantaneous active and reactive power flows required to the shunt inverter.

From Fig. 1, the circuit equation of shunt VSC of UPFC can be written in per unit as :

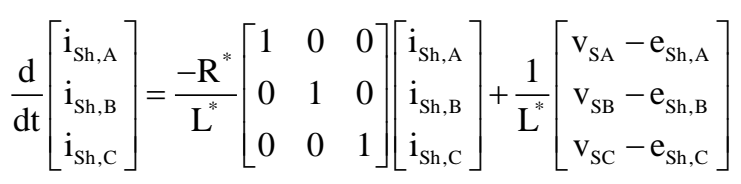


From [] the output values of controller of Shunt Converter to evaluate the d-q components of equivalent output voltage source, $\mathrm{V}_{\mathrm{Sh}, \mathrm{D}}$ and $\mathrm{V}_{\mathrm{Sh}, \mathrm{Q}}$ can be shown as below :

$\mathrm{v}_{\mathrm{Sh}, \mathrm{D}}=\mathrm{v}_{\mathrm{ID}}-\frac{\mathrm{L}_{\mathrm{Sh}}^{\prime}}{\omega} \mathrm{y}_{1 \mathrm{Sh}}$

$\mathrm{v}_{\mathrm{Sh}, \mathrm{Q}}=\mathrm{v}_{1 \mathrm{Q}}-\frac{\mathrm{L}_{\mathrm{Sh}}^{\prime}}{\omega} \mathrm{y}_{2 \mathrm{Sh}}=-\frac{\mathrm{L}_{\mathrm{Sh}}^{\prime}}{\omega} \mathrm{y}_{2 \mathrm{Sh}}$

$\mathrm{L}_{\mathrm{Sh}}^{\prime}=\frac{\omega \mathrm{L}_{\mathrm{Sh}}}{\mathrm{z}_{\mathrm{b}}}$

with assuming that $\mathrm{V}_{\mathrm{l}, \mathrm{D}}=\left|\mathrm{v}_{\mathrm{l}}\right| ; \mathrm{V}_{\mathrm{l}, \mathrm{Q}}=0$; the $\mathrm{L}_{\mathrm{Sh}}=$ shunt transformer leakage inductance; $\mathrm{Z}_{\mathrm{b}}$ is the base impedance. Therefore, the module and displacement angle of equivalent voltage source of shunt converter are calculated as follows :

$\left|\mathrm{V}_{\mathrm{Sh}}\right|=\sqrt{\mathrm{v}_{\mathrm{Sh}, \mathrm{D}}^{2}+\mathrm{v}_{\mathrm{Sh}, \mathrm{Q}}^{2}}$
$\alpha_{\mathrm{Sh}}=\operatorname{arctg} \frac{\mathrm{v}_{\mathrm{Sh}, \mathrm{Q}}}{\mathrm{v}_{\mathrm{Sh}, \mathrm{D}}}$

At the same manner, the output variables $\mathrm{y}_{1 \mathrm{Se}}, \mathrm{y}_{2 \mathrm{Se}}$ are used to evaluate the $\mathrm{d}-\mathrm{q}$ components of series converter of equivalent voltage source, $\mathrm{V}_{\mathrm{Se}, \mathrm{D}}$ and $\mathrm{V}_{\mathrm{Se}, \mathrm{Q}}$ by following equations :

$$
\begin{aligned}
& \mathrm{v}_{\mathrm{Se}, \mathrm{D}}=\left(\mathrm{v}_{\mathrm{ID}}-\mathrm{v}_{\mathrm{rD}}\right)-\frac{\mathrm{L}_{\mathrm{Se}}^{\prime}}{\omega} \mathrm{y}_{1 \mathrm{Se}} \\
& \mathrm{v}_{\mathrm{Se}, \mathrm{Q}}=\left(\mathrm{v}_{\mathrm{lQ}}-\mathrm{v}_{\mathrm{rQ}}\right)-\frac{\mathrm{L}_{\mathrm{Se}}^{\prime}}{\omega} \mathrm{y}_{2 \mathrm{Se}} \\
& \mathrm{L}_{\mathrm{Se}}^{\prime}=\frac{\omega\left(\mathrm{L}_{1}+\mathrm{L}_{\mathrm{Se}}\right)}{\mathrm{z}_{\mathrm{b}}} \\
& \left|\mathrm{V}_{\mathrm{Se}}\right|=\sqrt{\mathrm{v}_{\mathrm{Se}, \mathrm{D}}^{2}+\mathrm{v}_{\mathrm{Se}, \mathrm{Q}}^{2}} \\
& \alpha_{\mathrm{Se}}=\operatorname{arctg} \frac{\mathrm{v}_{\mathrm{Se}, \mathrm{Q}}}{\mathrm{v}_{\mathrm{Se}, \mathrm{D}}}
\end{aligned}
$$

with assuming that $\mathrm{V}_{1, \mathrm{D}}=\left|\mathrm{v}_{1}\right| ; \mathrm{V}_{1, \mathrm{Q}}=0$; the $\mathrm{L}_{\mathrm{Se}}=$ shunt transformer leakage inductance, and $\mathrm{L}_{1}$ is the line inductance. Therefore, the module and displacement angle of equivalent voltage source of shunt converter are calculated as follows :

\section{Converter control technique}

On the basic of operation requirements, the scheme of switching the converter's elements, such as GTO's or IGBT's, may be different. In this paper, as shown above, the PWM switching control technique has been considered. In this case the three phases of the output converter voltage result:

$$
\begin{aligned}
& \mathrm{v}_{\mathrm{yA}}=\frac{1}{2} \mathrm{~m}_{\mathrm{y}} \mathrm{V}_{\mathrm{DC}} \sin \left(\omega \mathrm{t}+\alpha_{\mathrm{y}}+\phi\right) \\
& \mathrm{v}_{\mathrm{yB}}=\frac{1}{2} \mathrm{~m}_{\mathrm{y}} \mathrm{V}_{\mathrm{DC}} \sin \left(\omega \mathrm{t}+\alpha_{\mathrm{y}}+\phi-120^{\circ}\right) \\
& \mathrm{v}_{\mathrm{yB}}=\frac{1}{2} \mathrm{~m}_{\mathrm{y}} \mathrm{V}_{\mathrm{DC}} \sin \left(\omega \mathrm{t}+\alpha_{\mathrm{y}}+\phi-240^{\circ}\right)
\end{aligned}
$$

here $\mathrm{m}_{\mathrm{y}}, \alpha_{\mathrm{y}}$ are the amplitude modulation ratio and phase angle of converter output voltage. These control variables are the input control signals of converters of UPFC according to PWM switching technique. If we apply (12) for Shunt converter, then $\mathrm{m}_{\mathrm{Sh}}$ is the index modulation and $\alpha_{\mathrm{Sh}}$ is the phase displacement angle with respect to $V_{1}$ (sending voltage). The same equation to Series converter, $m_{S e}$ is the index modulation and $\alpha_{\mathrm{Se}}$ is the phase displacement angle with respect to $\mathrm{V}_{\mathrm{l}}-\mathrm{V}_{\mathrm{r}}$ (compensation voltage). $\mathrm{V}_{\mathrm{DC}}$ is the value of voltage across the storage capacitor. 
Moreover the following relations are valid:

$$
\begin{aligned}
& \mathrm{m}_{\mathrm{y}}=2 \sqrt{2} \frac{\sqrt{\mathrm{v}_{\mathrm{yD}}^{2}+\mathrm{v}_{\mathrm{yQ}}^{2}}}{\mathrm{~V}_{\mathrm{DC}}} \\
& \alpha_{\mathrm{y}}=\operatorname{arctg}\left(\frac{\mathrm{v}_{\mathrm{yQ}}}{\mathrm{v}_{\mathrm{yD}}}\right)
\end{aligned}
$$

where $\mathrm{v}_{\mathrm{yD}}$ and $\mathrm{v}_{\mathrm{yQ}}$ are calculated by (8) and (11) respectively for the series and the shunt inverter.

In both control schemes the PI controllers is applied with parameters in dependence of converter characteristics, $\left(\mathrm{R}_{\mathrm{Se}}, \mathrm{L}_{\mathrm{Se}}\right)$, $\left(\mathrm{R}_{\mathrm{Sh}}, \mathrm{L}_{\mathrm{Sh}}\right)$ respectively the equivalent impedance of the series and shunt transformer and $\left(\mathrm{R}_{\text {line, }}, \mathrm{L}_{\text {line }}\right)$ the line equivalent impedance.

\section{DC-side control}

For normal operation of two VSC's in an UPFC, the DC voltage across the DC storage capacitor $\mathrm{C}_{\mathrm{S}}$ must be kept constant. This implies that the active power exchanged

between the UPFC and the power system is zero at steady state operation:

$\mathrm{p}_{\mathrm{Se}}+\mathrm{p}_{\mathrm{Sh}}=0$

that is, the active power delivered by the shunt inverter $\mathrm{p}_{\mathrm{Sh}}$ is equal to the active power exchange between the series inverter and the transmission line, $\mathrm{p}_{\mathrm{Se}}$. Hence, a DC voltage control system must be realized to keep $\mathrm{V}_{\mathrm{dc}}$ constant by taking the actual value of $\mathrm{v}_{\mathrm{dc}}$ as the feedback signal against a dc reference signal $\mathrm{V}^{*} \mathrm{dc}$ []. Moreover, assuming negligible the losses of the shunt and series converters and coupling transformers the actual value of the DC capacitor voltage is computed as :

$$
\frac{d v_{\mathrm{DC}}}{\mathrm{dt}}=\frac{\mathrm{p}_{\mathrm{Se}}+\mathrm{p}_{\mathrm{Sh}}}{\mathrm{C}_{\mathrm{DC}} \mathrm{v}_{\mathrm{DC}}}
$$

\section{SIMULATION AND RESULTS}

All the simulations were made using Matlab Power System Blockset and Simulink. The simulation results of the discrete UPFC model based 12 pulse-converter are the subject of this section. These results are obtained based on discrete modulation functions. A simple configuration of power system is applied to validate the new UPFC model based 12 pulse- converter. The test power system operates at $230 \mathrm{kV}$ and is shown in Fig.5. The generator is assumed to be an ideal voltage source behind an equivalent Thevenin impedance. The UPFC model is located at the sending end of the transmission line and is controlled in such a way to follow the changes in reference values of the line active and reactive power. The Shunt converter and Series converter are based on 12 pulse-converter with two level ignition signals. Besides, PWM technique with $1080 \mathrm{~Hz}$ carrier frequency, which is modeled by the discrete PWM pulse generator, is used to generate output voltage pulses of converters. This technique is very suitable for pulse control of UPFC and reduce total harmonic distortion of output voltage and line current. In those devices, input control variables of converter, such as amplitude modulation ratio and phase angle are output variables of close-loop power flow controller and close-loop DC voltage controller.

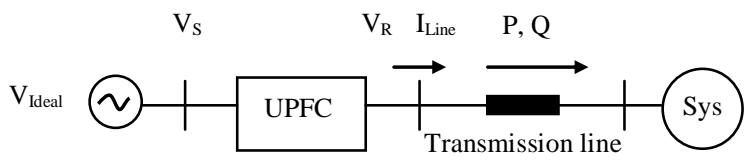

Fig.5 - Simple test system with UPFC.

The Fig. 8 displays DC voltage of UPFC. The real signal shape of DC voltage in discrete simulation is an oscillation curve around reference value according to pulses of PWM converter. In Fig.9 output voltage of Series converter is shown. It is a combination of two 6 pulse converters connected cascade together in which whole output voltage gains a better result of low harmonic content. This has a very important meaning in practice,....

In Fig.7, line current though UPFC is shown by discrete type. 
Moreover, this simulation proved that total harmonic content of line voltage at UPFC bus in new discrete 12 pulse converter model is lower that of conventional 6 pulse converter. This is illustrated in Fig.10.

OUTPUT VOLTAGE OF 12 PULSE-SERIES CONVERTER

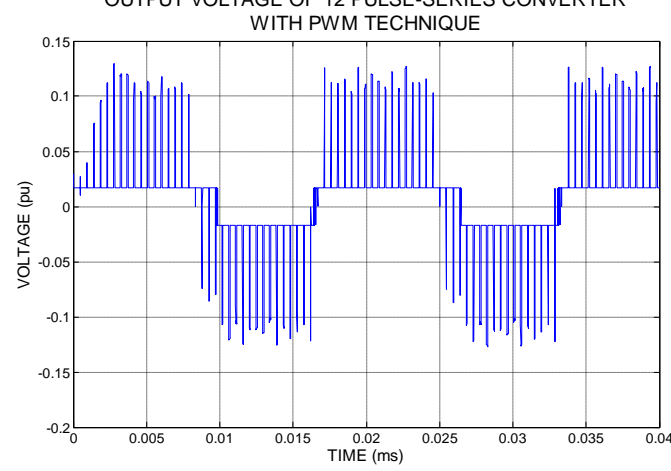

TIME (Sec)

Fig. 6 - Output voltage of 12 pulse series converter

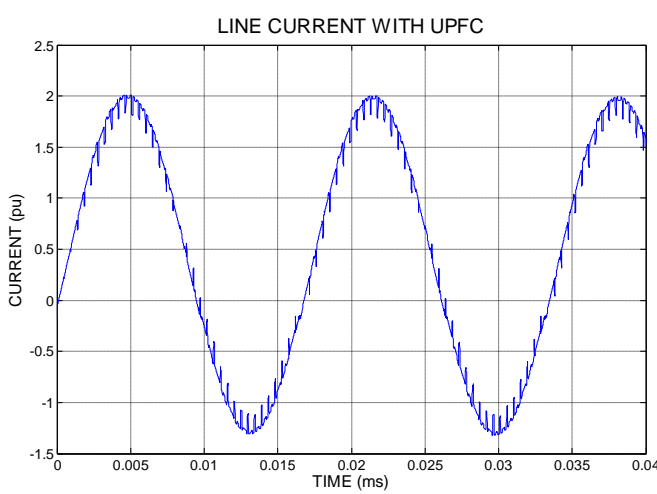

Fig. 7 - Current in transmission line DC VOLTAGE OF UPFC

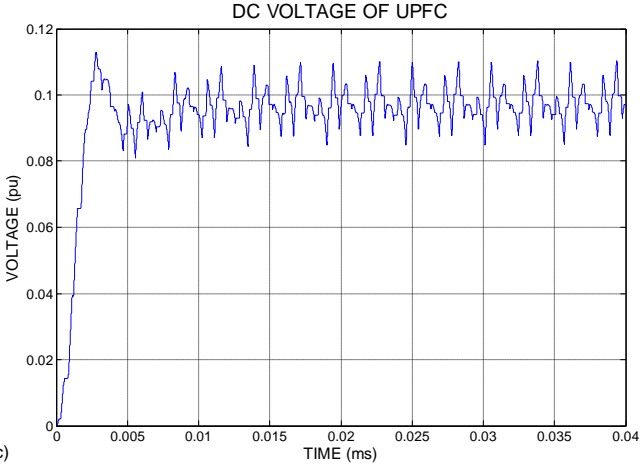

Fig.8 - DC voltage of UPFC

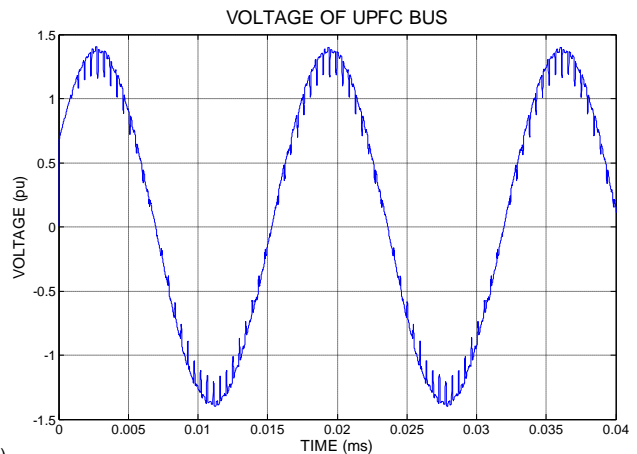

Fig.9 - Voltage in UPFC' received bus of transmission line 
In particular, the UPFC series inverter is simulated to maintain a power flow at the receiving end at 2 p.u. up to $5 / 60 \mathrm{sec}$. and after that at 4 p.u. as in Fig. 11 , and a reactive power flow is kept at 0.5 p.u. During simulation the active power exchange between the series converter and the power system is compensated by the active power exchange of the shunt converter, evaluated by the DC control system, so to maintain the dc voltage across the storage capacitor constant at the specified value as in Fig. 14.

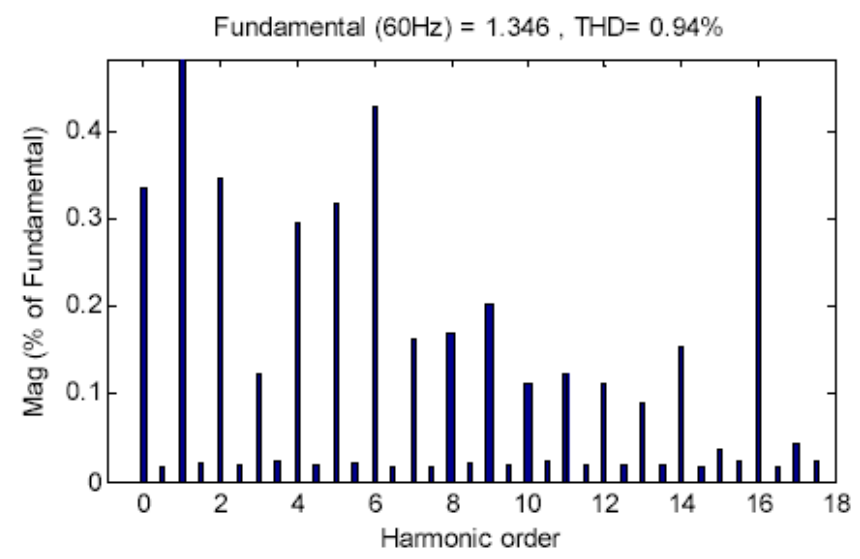

Fig.10-

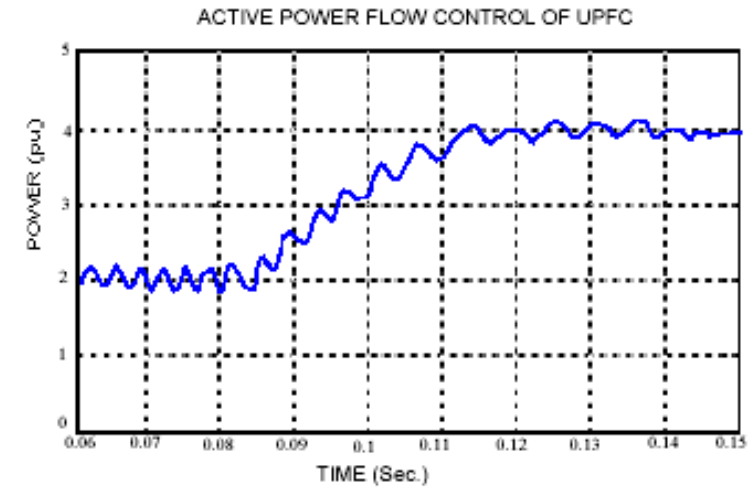

Fig.11 - Power flow characteristic of transmission line under dynamic control of UPFC

Fig.12, Fig.13, and Fig.14 are the demonstration of dynamic operating of UPFC with power value reference as stated above. In these figures, both values and shapes of voltage and current in transmission line are changed according to changing of modulation control variables adapted with active power references.

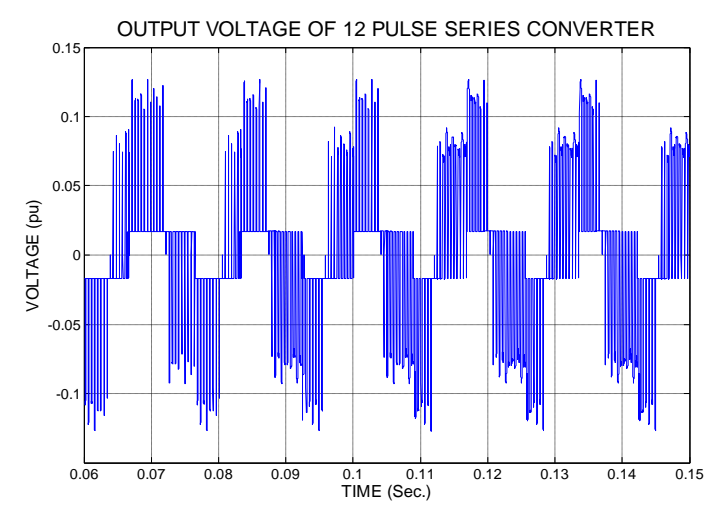

Fig. 12 - Output voltage responses of 12 pulse series converter in dynamic states. 


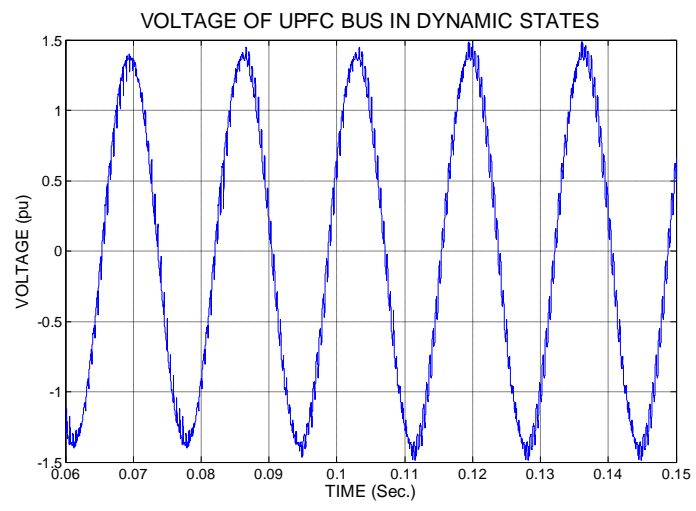

Fig.13 - Voltage characteristic of transmission line under dynamic control of UPFC

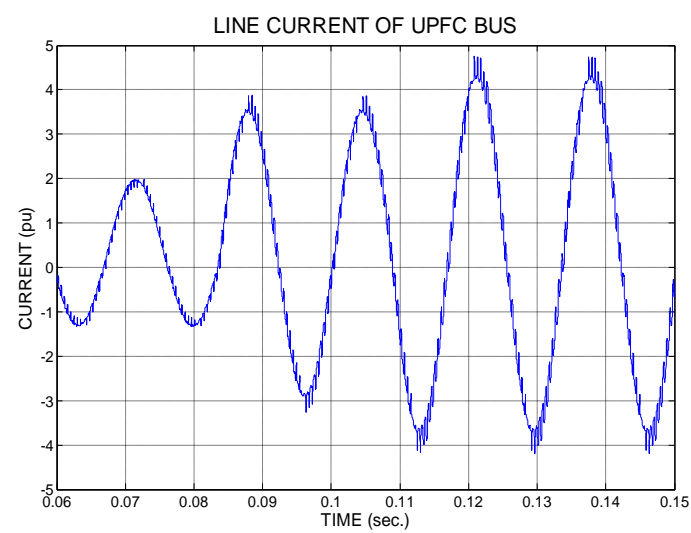

Fig. 14 - Current characteristic of transmission line under dynamic control of UPFC

\section{CONCLUSIONS}

This paper after a brief summary of the UPFC configuration based converter, illustrates in detail the control system model of UPFC with two separate control systems for the series and shunt inverters and a control for their coordination. Finally, a discrete simulation of new UPFC model based 12 pulse converter using Matlab/Simulink as simulation program is shown and some simulation results are illustrated to validate the implemented this UPFC model. Especially, the simulation results have provided the practical operating processes of UPFC and converter. These give us the practical views of action of every part of devices and responses of power system under UPFC working. The results are obtained for a PWM-based control technique, but it's very simple to modify the converter control technique such as phase control.

However, this new discrete UPFC model based on 12 pulse converter seems not to be suitable for application in contingency analysis because it is quite complex in separating control systems of Shunt converter and series converter properly with maintained control quality A UPFC with matrix converter is useful only for steady operation modes.

This new discrete 12 pulse converter model will be modified to be able to perform a damping oscillation operating functions in such a way in the future researches.

\section{REFERENCES}

[1] L. Gyugyi, C.D. Shauder, S.L. Williams, T.R. Rietman, D.R. Torgerson, A. Edris. "The unified power flow controller: A new approach to power transmission control”, IEEE Trans. On Power Delivery, Vol.10, No.2, April 1995, pp.1085-1097.

[2] H.Fujita, Y. Watanabe, H.Akagi. "Control and analysis of a unified power flow controller". IEEE Trans. On Power Electronics, Vol.14, No.6, Nov. 1999. 